\title{
Subducted oceanic crust as the origin of seismically slow lower-mantle structures
}

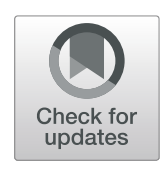

Timothy D. Jones ${ }^{1 *}$, Ross R. Maguire ${ }^{2,3}$, Peter E. van Keken ${ }^{1}$, Jeroen Ritsema ${ }^{4}$ and Paula Koelemeijer ${ }^{5}$

\begin{abstract}
Mantle tomography reveals the existence of two large low-shear-velocity provinces (LLSVPs) at the base of the mantle. We examine here the hypothesis that they are piles of oceanic crust that have steadily accumulated and warmed over billions of years. We use existing global geodynamic models in which dense oceanic crust forms at divergent plate boundaries and subducts at convergent ones. The model suite covers the predicted density range for oceanic crust over lower mantle conditions. To meaningfully compare our geodynamic models to tomographic structures, we convert them into models of seismic wavespeed and explicitly account for the limited resolving power of tomography. Our results demonstrate that long-term recycling of dense oceanic crust naturally leads to the formation of thermochemical piles with seismic characteristics similar to the LLSVPs. The extent to which oceanic crust contributes to the LLSVPS depends upon its density in the lower mantle for which accurate data is lacking. We find that the LLSVPs are not composed solely of oceanic crust. Rather, they are basalt rich at their base (bottom 100-200 km) and grade into peridotite toward their sides and top with the strength of their seismic signature arising from the dominant role of temperature. We conclude that recycling of oceanic crust, if sufficiently dense, has a strong influence on the thermal and chemical evolution of Earth's mantle.
\end{abstract}

Keywords: Geodynamical modeling, Mantle structure, Seismic tomography

\section{Introduction}

Tomographic models reveal the presence of two large anomalous structures in the lowermost mantle. These large low-shear velocity provinces (LLSVPs) are surrounded by high shear-wave velocity regions that are associated with past subduction (Fig. 1; Tanaka et al. 2009; Ritsema et al. 2011; and and Cottaar and Lekic 2016). The origin of the LLSVPs and their connection to mantle dynamics and the long-term chemical evolution of the planet remain unclear (see McNamara (2019) for a recent overview). Suggested origins include large-scale thermal upwellings (e.g.,Schubert et al. 2004; Davies et al.2015; and Koelemeijer et al. 2017), dense piles of primordial and compositionally distinct mantle (e.g., Garnero and McNamara 2008; Burke et al. 2008), and accumulations

\footnotetext{
*Correspondence: tjones@carnegiescience.edu

'Department of Terrestrial Magnetism, Carnegie Institution for Science, 5241 Broad Branch Road NW, Washington, DC, 20015 USA

Full list of author information is available at the end of the article
}

of recycled oceanic crust (e.g., Christensen and Hofmann 1994; Nakagawa et al. 2009, 2010). Markedly different interpretations of LLSVPs persist because there is no unique cause of seismic velocity anomalies in the mantle, but there are many plausible ones. For example, the low-shear velocity anomaly $\left(\delta \ln \mathrm{V}_{s} \approx-2 \%\right)$ associated with LLSVPs may be equally well explained by an increase in temperature (Schuberth et al. 2009), a compositional change (McNamara and Zhong 2005), the presence of melt (Lee et al. 2010), or a combination thereof ( $\mathrm{Li}$ and McNamara 2013; Ballmer et al. 2016). The elevated ratio between shear and compressional wavespeed anomalies within LLSVPs (Robertson and Woodhouse 1995; Masters et al. 2000; Romanowicz 2001; Moulik and Ekström 2016) is often regarded as evidence that they are thermochemical in origin, but it can also indicate the presence of post-perovskite without requiring a contribution from large-scale chemical variations (Koelemeijer et al. 2018). Measurements of solid-Earth tides (Lau et al. 2017) and 


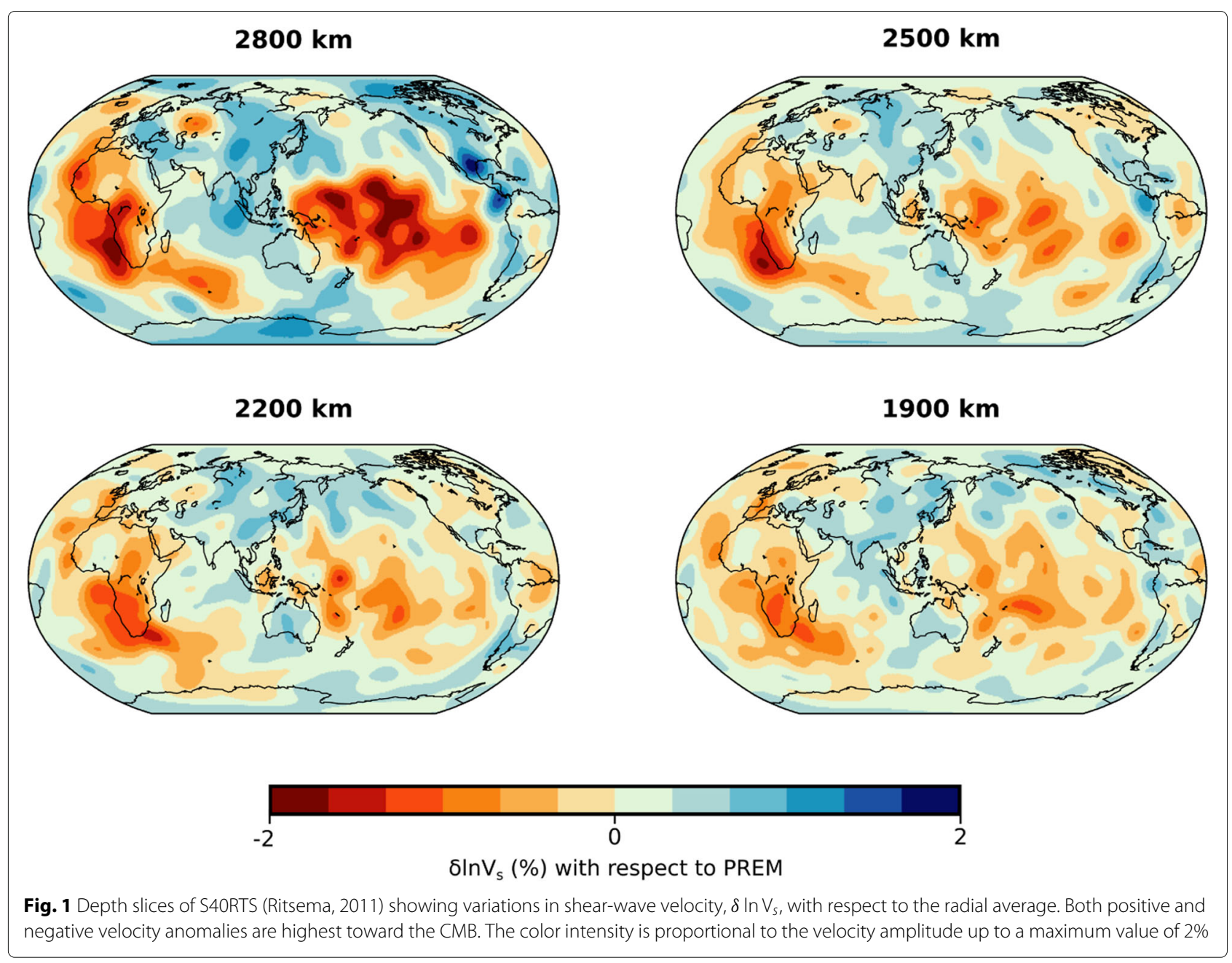

normal mode splitting functions (e.g., Ishii and Tromp 1999; Trampert et al. 2004; Moulik and Ekström 2016; and Koelemeijer et al. 2016) suggest that the LLSVPs have a higher than average density across the bottom two thirds of their depth range. However, constraining the density from low-frequency data depends on the chosen set of normal modes, on how CMB topography is modeled, and on the theoretical simplifications made to model the data (e.g., Koelemeijer et al. 2017; Akbarashrafi et al. 2018).

In this study, we will test the hypothesis that LLSVPs are accumulations of dense recycled oceanic crust. We are motivated in particular by geodynamical studies that show that the long-term recycling of oceanic crust can significantly contribute to the formation of warm but dense pools of compositionally distinct material at the base of the mantle (Fig. 2; Christensen and Hofmann 1994; Brandenburg and van Keken 2007; Brandenburg et al. 2008; and Nakagawa and Tackley 2008). We will focus on how well thermochemical model simulations predict the seismological characteristics of LLSVPs by projecting the temperature and composition to seismic velocity. We will then test how well such velocity structures are resolved in the shear-wave velocity model, S40RTS (Ritsema et al. 2011), and the combined shear- and compressional-wave velocity model, SP12RTS (Koelemeijer et al. 2016).

As oceanic lithosphere subducts, three distinct components are recycled back into the mantle: a thin basaltic crust and a thicker base of harzburgite on top of the more primitive peridotite from which the crust was extracted. Due to convective stirring of these components, the mantle composition is an evolving mixture of the three endmember compositions. To simplify the description below, we will refer to end-member basaltic, harzburgitic, and peridotitic compositions as "basalt", "harzburgite", and "peridotite", respectively, and, where relevant, will use subscripts $B, H$, and $P$ to identify them.

Mineral physics experiments indicate that the basaltic component is denser than ambient mantle through most of Earth's mantle with a relative density contrast $\delta \ln \rho$ of up to $2-7 \%$, except near the surface and in the uppermost lower mantle (Ringwood and Irifune 1988; 
a) $\delta \ln \rho=0 \%$

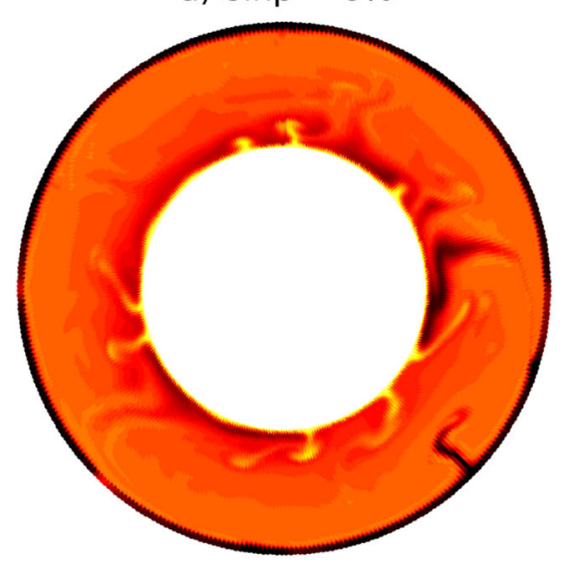

c) $\delta \ln \rho=3.8 \%$

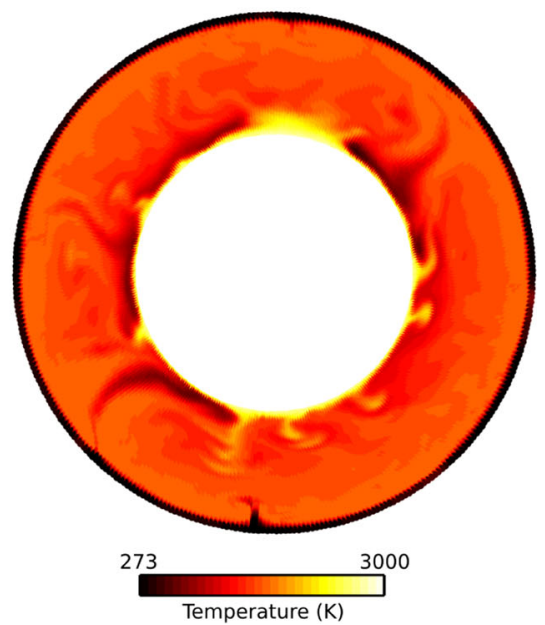

b) $\delta \ln \rho=0 \%$

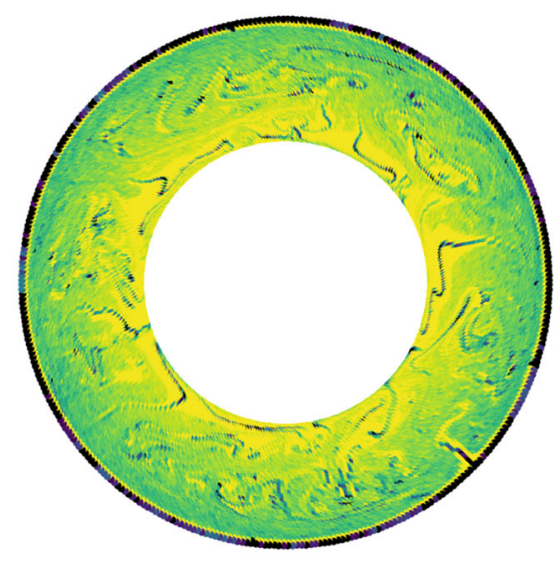

d) $\delta \ln \rho=3.8 \%$

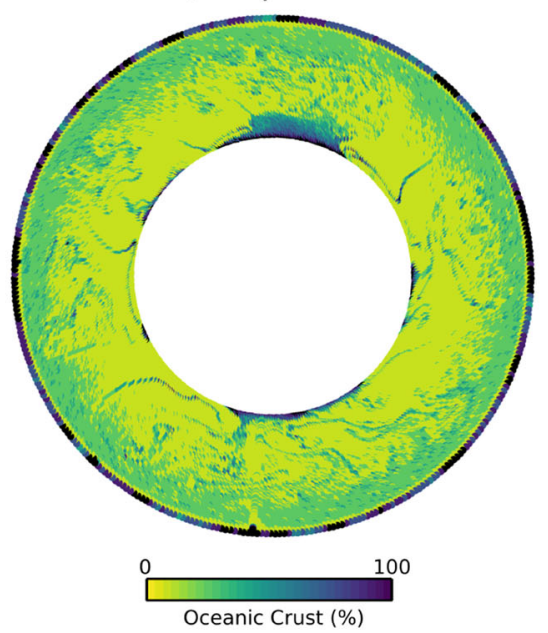

Fig. 2 Plot of temperature and composition fields for Brandenburg et al. (2008) models for $\delta \ln \rho$ of $0 \%$ (a, b) and 3.8\% (c, d), where we use the non-linear radial projection of the models onto Earth coordinates. In both cases, recently subducted oceanic crust meets the CMB and the low viscosity upper mantle has been homogenized by convective stirring relative to the lower mantle. When $\delta$ In $\rho=0 \%$, oceanic crust is somewhat evenly distributed throughout the lower mantle. In contrast, when $\delta \ln \rho=3.8 \%$, oceanic crust accumulates and the CMB forms sharp piles

Ringwood 1990; Hirose et al. 1999; Aoki and Takahashi 2004; Hirose et al. 2005; Ricolleau et al. 2010; Tsuchiya 2011). Under these conditions, numerical experiments predict that the oceanic crust will accumulate at the core-mantle-boundary (CMB) (Christensen and Hofmann 1994; Davies 2002; Xie and Tackley 2004; Brandenburg and van Keken 2007). The presence of recycled oceanic crust as a major component of mantle plumes (Hofmann and White 1982) is empirical evidence that at least some portion of subducted material reaches the CMB.

The models presented in this study follow the approach of Christensen and Hofmann (1994) (herein CH94) who assumed that the basalt remains denser throughout the mantle and retains a constant density contrast with the ambient mantle. $\mathrm{CH} 94$ found that at sufficiently large density excess, the subducted oceanic crust accumulates at the $\mathrm{CMB}$ where it is swept into piles and mixes with the ambient mantle. They concluded that this process could not only account for important features of Earth's chemical evolution but may also explain seismic heterogeneity in the D" layer.

Due to computational limitations at the time, $\mathrm{CH} 94$ performed dynamical computations at a convective vigor that is significantly below that of present day Earth and used a scaling relationship to extrapolate their findings to models with present-day plate velocities. Brandenburg and van Keken (2007) explicitly showed that this extrapolation is an accurate approximation. Brandenburg et al. (2008) (herein BB08) further extended the study of CH94 by exploring the effects of crustal recycling in models with force-balanced plates and with Earth-like convective vigor. Their results confirmed the findings of $\mathrm{CH} 94$. They also showed that the formation and recycling of oceanic 
crust could contribute to the HIMU-DMM-EMI diversity of Ocean Island Basalt (OIB) and Mid-Oceanic Ridge Basalt (MORB) in multiple isotope systems.

The BB08 study confirmed that recycled dense oceanic crust forms thermochemical piles. These piles naturally form sharp edges, as observed in seismological studies ( $\mathrm{Ni}$ et al. 2002; Ritsema et al. 1998), and they are broadly consistent with the size and shape of LLSVPs (Fig. 2 frames $\mathrm{c}$ and d). However, any assessment of similarity between thermochemical models and global tomographic models must take into account the limited spatial resolution of seismic tomography. As earlier studies have shown, shearwave velocity perturbations can be reduced, smeared, and spatially shifted due to the effects of uneven data coverage and damping (Ritsema et al. 2007; Schuberth et al. 2009). In this paper, we will map the temperature and compositional fields of the BB08 models into seismic velocity and will then account for the parameterization and regularization parameters of S40RTS (Ritsema et al. 2011) and SP12RTS (Koelemeijer et al. 2016). Our analysis of these seismologically filtered geodynamical models will include a comparison of their spectral content and radially averaged profiles to that of S40RTS and SP12RTS. We conclude that the recycling of oceanic crust, by itself or in addition to other processes, can explain the imaged seismic heterogeneity that is expressed by the LLSVPs as long as the oceanic crust has a moderate to high excess density with respect to the ambient mantle.

\section{Methods}

\section{Geodynamic models}

The BB08 models are finite element solutions of convective flow in an incompressible fluid at an infinite Prandtl number driven by thermal and chemical buoyancy. The models are based on a 2D cylindrical geometry with a reduced core radius to mimic the heat loss characteristics of Earth (van Keken 2001).

The models use a force-balanced plate approach (Gable et al. 1991) that yields average surface velocities and surface heatflow consistent with values observed today. This sets up energetically consistent convection with prescribed zones of divergence and convergence where oceanic crust forms and subduct, respectively. The resolution of the models varies from $50 \mathrm{~km}$ in the middlelower mantle to $13 \mathrm{~km}$ at both the surface and $\mathrm{CMB}$, such that the thermal boundary layers, of characteristic thickness $\sim 100 \mathrm{~km}$ are adequately resolved. At divergent zones, a melting parameterization generates basaltic crust with a harzburgite residue from the peridotitic mantle to form oceanic lithosphere. When this lithosphere subducts at convergent zones, it sinks to the base of the mantle under negative thermal buoyancy before mixing with the surrounding mantle. We represent the peridotitic composition by tracers that are spaced, on average, at $5 \mathrm{~km}$ and that concentrate by a factor of 8 when the oceanic crust is formed such that a $\sim 10-\mathrm{km}$-thick basaltic crust is adequately modeled.

In non-dimensional form, the governing equations are the conservation of mass:

$$
\nabla \cdot \boldsymbol{u}=0
$$

the conservation of momentum:

$$
-\nabla P+\nabla \cdot(\eta \underline{\dot{\epsilon}})=[R a T-R c C] \hat{\boldsymbol{g}}
$$

and the conservation of heat:

$$
\frac{\partial T}{\partial t}+(\boldsymbol{u} \cdot \nabla) T=\nabla^{2} T+Q
$$

where $\boldsymbol{u}$ is the velocity vector, $P$ the dynamic pressure, $t$ time, $T$ the temperature, and $\hat{\boldsymbol{g}}$ the unit vector in the direction of gravity. $C$ is the chemical composition, $\eta$ the non-dimensional dynamic viscosity, and $Q$ is the volumetric internal heating. $\underline{\dot{\epsilon}}$ is the strain-rate tensor $\underline{\dot{\epsilon}}=$ $\left(\nabla u+\nabla u^{T}\right) \cdot R a$ is the thermal Rayleigh number:

$$
R a=\frac{\rho_{0} g \alpha_{0} \Delta T h^{3}}{\kappa_{0} \eta_{0}}
$$

where $\Delta T$ is the assumed temperature contrast across the mantle and $h$ is the thickness of the mantle. $\rho_{0}, \kappa_{0}, \alpha_{0}$, and $\eta_{0}$ are the reference values for density, thermal diffusivity, thermal expansivity, and dynamic viscosity, respectively. $R c$ is the compositional Rayleigh number:

$$
R c=\frac{\Delta \rho_{0} g h^{3}}{\kappa \eta_{0}}
$$

where $\Delta \rho_{0}$ is related to the density contrast between the oceanic crust and the depleted mantle (see below). For reference values, see Table 1 . The models assume constant expansivity and diffusivity, and a temperature- and depth-dependent viscosity of the non-dimensional form

$$
\eta(T, z)=\eta_{z}(z) \exp (-b T)
$$

where $z$ is depth, $b=\ln (1000)$, and $\eta_{z}$ is 1000 in the lithosphere, 1 in the upper mantle, and 30 in the lower mantle.

Table 1 Parameters common to all cases examined and their reference values

\begin{tabular}{llll}
\hline Symbol & Parameter & Reference value & Units \\
\hline$h$ & Thickness & 2885 & $\mathrm{~km}$ \\
$\alpha_{0}$ & Thermal expansion coefficient & $3 \times 10^{-5}$ & $\mathrm{~K}^{-1}$ \\
$\eta_{0}$ & Lower mantle viscosity & $10^{22}$ & $\mathrm{~Pa} \mathrm{~s}$ \\
$\rho_{0}$ & Density & 4500 & $\mathrm{~kg} \mathrm{~m}^{-3}$ \\
$\kappa_{0}$ & Thermal diffusivity & $10^{-6}$ & $\mathrm{~m}^{2} \mathrm{~s}^{-1}$ \\
$\Delta T$ & Temperature contrast & 3000 & $\mathrm{~K}$ \\
\hline
\end{tabular}


BB08 unfortunately introduced a number of notation errors that include typos in the equations (e.g., their equation (10) should read $f=N /(N+7 M)$, not $f=1 /(N+7 M))$ and inverted the meaning of the term "extraction coefficient" where "retention coefficient" was intended. It also obscured the definition of the eclogite excess density (EED) as it was not fully defined. The EED used in their paper was defined as $\mathrm{EED}=R c / R a=\Delta \rho /\left(\rho_{0} \alpha_{0} \Delta T\right)$ and ranged from 0 to $10 \%$. The composition function $C$ (Eq. 2) is 1 for peridotite, 0 for harzburgite (which has density $\rho_{0}$ ), and 8 for basalt. This means that the dimensional density contrast of the oceanic crust to depleted mantle $\Delta \rho_{B-H}=\rho_{B}-$ $\rho_{H}$ can be found by multiplying EED by $8 \rho_{0} \alpha_{0} \Delta T$. The more commonly used expression for relative excess density $\partial \ln \rho=\left(\rho_{B}-\rho_{P}\right) / \rho_{P}$ is with respect to ambient mantle found by multiplying EED by $7 \rho_{0} \alpha_{0} \Delta T$. Using $\rho_{0}=4500 \mathrm{~kg} / \mathrm{m}^{3}, \alpha_{0}=3 \times 10^{-5} / \mathrm{K}$, and $\Delta T=3000 \mathrm{~K}$, we find $\Delta \rho_{B-P}=\mathrm{EED} \times 2840 \mathrm{~kg} / \mathrm{m}^{3}$. For $\mathrm{EED}=10 \%$ (the maximum value considered), we find a dimensional density of the oceanic crust to be $\rho_{B}=4824 \mathrm{~kg} / \mathrm{m}^{3}$ which translates to a relative density increase of $\delta \ln \rho=6.2 \%$.

We select seven simulations that are similar to those in BB08 except that the models have been evaluated on a higher resolution finite element mesh (with $70 \mathrm{~K}$ vs. $46 \mathrm{~K}$ nodal points) and a larger number of tracers (3.7 $\mathrm{M}$ vs. $2.5 \mathrm{M})$. Between each model, we vary only the the density difference between basalt and harzburgite. This has some control over the dynamics, which leads to differences in the spatial distribution of chemical heterogeneity throughout the mantle.

Each simulation starts from snapshot of a purely thermal convection simulation at $R a=5 \times 10^{6}$ that was evolved for a sufficiently long time to let any of the transients associated with the initial conditions disappear. We then model oceanic crust formation and recycling for a period equivalent to $4.5 \mathrm{Byr}$ and for various values for $R c$ (between 0 and $5 \times 10^{5}$ ). Piles of recycled crust build up over time for $R c>0$. Since we keep $R c / R a$ fixed for each simulation, the accumulation of oceanic crust for the higher $\delta \ln \rho$ models tends to make the convection slightly more sluggish towards the end of the model evolution (consistent with BB08).

\section{Model selection and seismic wavespeed conversion}

We first select a time slice from the past $2.5 \mathrm{Gyr}$ of each simulation in which a broad thermochemical pile is present (for Rc $>0$ ). Piles tend not to approach the size of LLSVPs earlier than about $2 \mathrm{Ga}$ and are more robust for higher $\delta \ln \rho$. We also use a time-slice for $R c=0$ for comparison.

Two steps are required to create an Earth-like geometry from the 2D cylindrical models. We use a non-linear radial projection of the models onto Earth coordinates (i.e., the non-dimensional core radius 0.492 maps onto a $\mathrm{CMB}$ depth of $2885 \mathrm{~km}$ and the non-dimensional surface radius 1.492 corresponds to depth $0 \mathrm{~km}$; van Keken (2001)). We then project a $180^{\circ}$ section of the geodynamic model into an axisymmetric spherical shell representation that is representative of a fully 3D spherical model with the important constraint that the thermochemical pile is centered about the rotation axis. This effectively imposes the dome-like geometry characteristic of LLSVPs. Structures away from the rotation axis thus become ring-like.

The 3D spherical model is then converted from temperature and composition to seismic wavespeed using the following approach. First, we convert potential temperature to absolute temperature by adding an adiabatic gradient for a pyrolite composition. This step is required because the geodynamic simulations assume the incompressible Boussinesq approximation.

Next, we map the pressure $P$, temperature $T$, and basalt fraction $f$ to seismic shear-wave velocity $V_{s}$ and compressional-wave velocity $V_{p}$ using the method of $\mathrm{Xu}$ et al. (2008), where it is assumed that the mantle can be represented as a mechanical mixture of basalt and harzburgite. The bulk composition of the two end members are defined in terms of the proportions of the oxides $\mathrm{SiO}_{2}, \mathrm{Na}_{2} \mathrm{O}, \mathrm{CaO}, \mathrm{FeO}, \mathrm{MgO}$, and $\mathrm{Al}_{2} \mathrm{O}_{3}$.

We use the composition of basalt from Workman and Hart (2005) and the composition of harzburgite from Baker and Beckett (1999). The stable mineral assemblage and associated anharmonic seismic wavespeeds are computed for both basalt and harzburgite using Perple_X (Connolly 2005) and the mineral elastic parameter database of Stixrude and Lithgow-Bertelloni (2011).

The anharmonic seismic wavespeeds are corrected for frequency-dependent effects of attenuation using Maguire et al. (2016) attenuation model. The seismic wave speed $\mathrm{V}\left(V_{s}\right.$ or $\left.V_{p}\right)$ of intermediate compositions is taken as the linear combination of the end member compositions basalt and harzburgite:

$$
\mathrm{V}(P, T, f)=f \mathrm{~V}^{B}(P, T)+(1-f) \mathrm{V}^{H}(P, T)
$$

The velocity anomaly $\delta \ln \mathrm{V}$ is computed relative to the radially averaged seismic structure.

\section{Reparameterization and the seismic resolution operator}

To meaningfully compare geodynamic models with tomographic models, we must account for the parameterization and limited resolution of the latter. This process is illustrated in Fig. 3. We begin by reparameterizing our geodynamically predicted wavespeed model onto the basis of S40RTS. Lateral variations of $\delta \ln \mathrm{V}_{s}$ are described using spherical harmonics up to degree and order 40 , and depth variations by 21 vertical splines. 
a) Dynamic Model

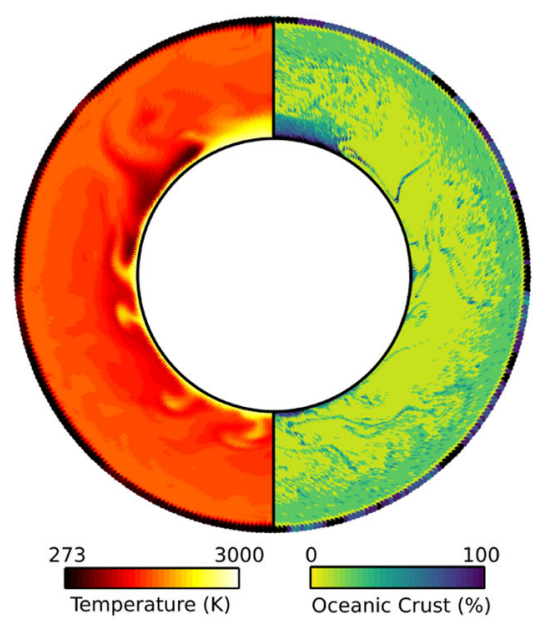

c) Reparameterized
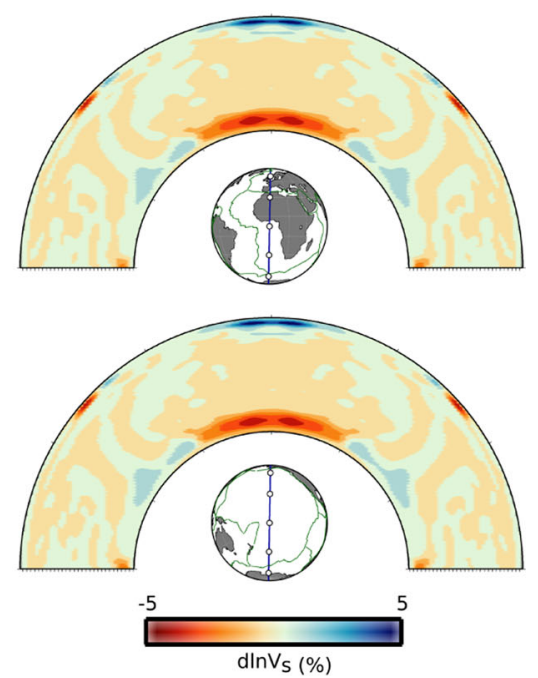

b) Predicted seismic wavespeed

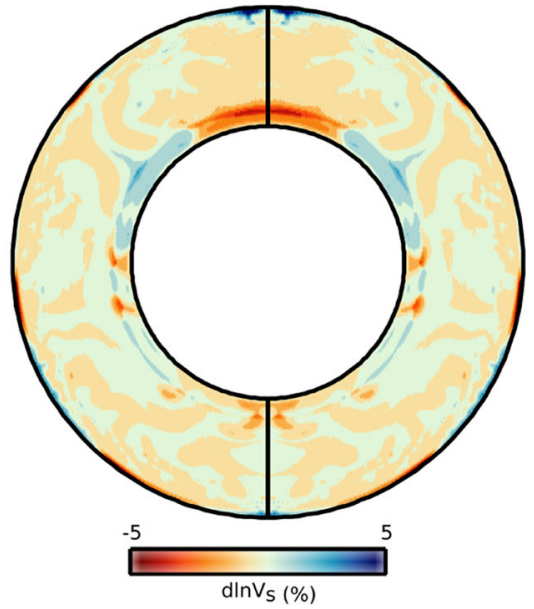

d) Reparameterized and filtered
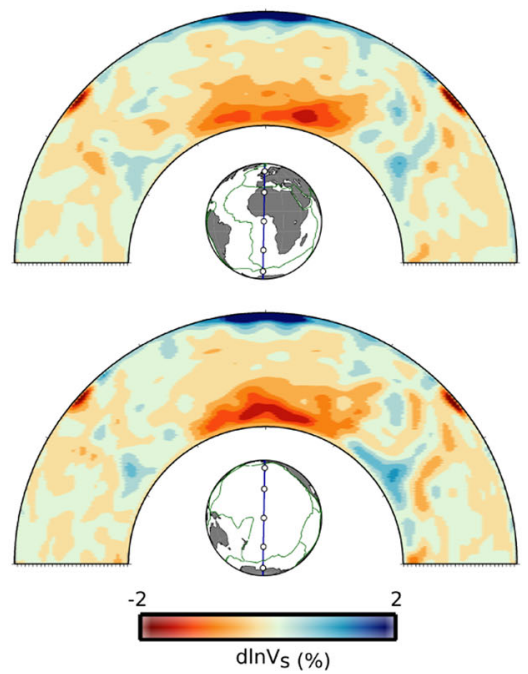

Fig. 3 Illustration of steps in our method to convert dynamic models into seismic velocity models and account for the parameterization and resolution of S40RTS. a Dynamic model, where $\delta \ln \rho=3.8 \%$, showing temperature and composition fields. b Predicted seismic wavespeed model showing $\delta \ln V_{s}$ variations with respect to the radial average. c Reparameterized model of $\delta \ln V_{s}$ on the basis of S40RTS. d Recovered $\delta \ln V_{s}$ after accounting for damping and uneven sampling of S40RTS. The geographic location of depth slice is provided in by the black vertical line through the globe

Following the approach of Ritsema et al. (2007), we define the resolution operator to be $\mathcal{R}=\mathbf{G}^{\dagger} \mathbf{G}$, where $\mathbf{G}$ is the operator of the seismic forward problem and $\mathbf{G}^{\dagger}$ is its generalized inverse. We then modify our reparameterized model of seismic wavespeed (the input model $\mathbf{m}^{\mathrm{IN}}$ ) by multiplying it with $\mathcal{R}$ to obtain a filtered output model, $\mathbf{m}^{\text {OUT }}$, as if imaged by tomographic inversion:

$$
\mathbf{m}^{\mathrm{OUT}}=\mathcal{R} \mathbf{m}^{\mathrm{IN}}
$$

where $\mathcal{R}$ is a complete description of the variable spatial resolution of S40RTS. We compute $\mathcal{R}$ for the same damping parameter as that used in S40RTS.
To explore how both $\delta \ln \mathrm{V}_{s}$ and $\delta \ln \mathrm{V}_{p}$ are recovered after tomographic filtering, we repeat this processes using $\mathcal{R}$ from the joint $\mathrm{V}_{s}$ and $\mathrm{V}_{p}$ tomography model SP12RTS. SP12RTS uses a similar model parameterization to S40RTS but only up to spherical harmonic degree 12. Since SP12RTS incorporates information from both $V_{s}$ and $V_{p}$, the model vector $\mathbf{m}$ consists of two parts:

$$
\mathbf{m}=\left(\begin{array}{l}
\mathbf{S} \\
\mathbf{P}
\end{array}\right)
$$

where $\mathbf{S}$ and $\mathbf{P}$ are model vectors describing $\operatorname{d} \ln V_{s}$ and $\operatorname{dln} V_{p}$, respectively. Therefore, Eq. 8 becomes: 


$$
\left(\begin{array}{l}
\mathbf{S}^{\text {OUT }} \\
\mathbf{P}^{\text {OUT }}
\end{array}\right)=\left(\begin{array}{ll}
\mathcal{R}_{\mathrm{SS}} & \mathcal{R}_{\mathrm{SP}} \\
\mathcal{R}_{\mathrm{PS}} & \mathcal{R}_{\mathrm{PP}}
\end{array}\right)\left(\begin{array}{l}
\mathbf{S}^{\mathrm{IN}} \\
\mathbf{P}^{\mathrm{IN}}
\end{array}\right)
$$

where the diagonal blocks, $\mathcal{R}_{\mathrm{SS}}$ and $\mathcal{R}_{\mathrm{PP}}$, describe how $V_{s}$ and $V_{p}$ map into $V_{s}$ and $V_{p}$, respectively, while the offdiagonal blocks, $\mathcal{R}_{\mathrm{SP}}$ and $\mathcal{R}_{\mathrm{PS}}$, describe how $V_{s}$ and $V_{p}$ map into each other.

\section{Results}

\section{Effects of reparameterization and tomographic filtering}

We first look at the effects of the filtering processes itself on $\delta \ln$ Vs. Figure 3 illustrates how reparameterization and $\mathcal{R}$ modify the input model to an output model with the resolution of S40RTS. Only the broadest scale of seismic heterogeneity of the input model is preserved following the filtering process. The highest $\delta \ln \mathrm{V}_{s}$ anomalies are in the uppermost mantle, and the relative position of high and low seismic velocity features are well preserved in the lower mantle.

The most pronounced effects are amplitude reduction and smoothing. These effects are accentuated where data coverage is sparse. This is for example of the case beneath the African plate (Fig. 4, left column), where $\delta \ln V_{s}$ anomalies in the same filtered geodynamic input model are smaller and smoother than beneath the Pacific plate (Fig. 4, right column). Consequently, cold subducted lithosphere and the thermochemical piles are more dominant features of the lower mantle in our Pacific crosssections. Where data coverage is particularly poor, low $\delta \ln \mathrm{V}_{s}$ anomalies disappear entirely after filtering. For example, subducted lithosphere is imaged along the $\mathrm{CMB}$ in the Pacific cross-section with $\delta \ln \mathrm{V}_{s} \sim 0.5 \%$ (Fig. 4, $\delta \ln \rho=3.1 \%$ ), but the same structure is absent in the African cross-section.

\section{Effects of $\delta \ln \rho$}

The spatial patterns of $\delta \ln V s$ for all filtered dynamic models and along radial segments of S40RTS are illustrated in Fig. 4. In the isochemical convection case, plume clusters (Fig. 4, bottom row) are imaged as regions of low $\delta \ln \mathrm{V}_{s}$ in the lower mantle, but these are significantly smaller and of weaker amplitude than LLSVPs in S40RTS. Furthermore, regions of high $\delta \ln \mathrm{V}_{s}$ are absent from the lowermost mantle.

By comparison, regions of strongly negative $\delta \ln \mathrm{V}_{s}$ for the thermochemical convection cases are broader and of stronger amplitude. Their size does not reflect that of the basaltic crust piles. Instead, the margins of the low $\delta \ln \mathrm{V}_{s}$ regions map onto the thermal anomaly associated with the basaltic crust piles. This implies that LLSVPs should not be interpreted as pure oceanic crust. Rather, under the parameters explored here, they are basalt rich at their base (bottom 100-200 km) and grade into peridotite toward their sides and top, which can reach mid-mantle depths.
The range of $\delta \ln \mathrm{V}_{s}$ in all thermochemical simulations is comparable to that of S40RTS after tomographic filtering is applied. However, the low velocity structures resemble LLSVPs in their size and strength only when $\delta \ln \rho \geq 3.1 \%$ so that enough basaltic crust accumulates at the CMB.

The thermochemical piles are generally flanked by moderate-to-high $\delta \ln \mathrm{V}_{s}$ anomalies, corresponding to cold lithosphere that has recently subducted. In these models, the subducted lithosphere sweeps the hot, dense material into piles. This is consistent with S40RTS, and other tomographic models, that show LLSVPs surrounded by a ring of high seismic velocity (e.g., Dziewonski et al. 1977; Grand et al. 1997; and Kennett et al. 1998).

In contrast to S40RTS, subducted lithosphere in a number of the filtered models is coherently imaged through the entire mantle. This indicates that subducted lithosphere in those cross sections has a higher temperature anomaly or are broader than subducted slabs in Earth's mantle. Our models have important limitations that may explain this difference. We force an axisymmetric spherical symmetry on the models causing the downwellings in the geodynamical models to be projected as ring-like features which likely are recovered with higher amplitude and geographical extent than subduction zones in the Earth. Additionally, on Earth, subduction is one-sided and occurs at a range of angles while in the geodynamic models, subduction is two-sided and the slabs sink almost exclusively vertical.

Given that our models are two-dimensional and have dynamic plates, we can neither draw meaning from geographical correlations nor impose past plate motions. We therefore compare the similarity of cross sections of S40RTS and filtered geodynamic models in two ways. First, we compare the heterogeneity spectra of $\delta \ln V_{s}$ by computing the power spectral density (PSD) at each depth (Figs. 5 and 6). This gives the power as a function of wavenumber $k$ that represents the number of wavelengths per $360^{\circ}$ and thus are analogous to spherical harmonic degree. The heterogeneity spectrum is normalized by the maximum of the PSD at each depth. Second, we compare the root-mean-square (RMS) of $\delta \ln \mathrm{V}_{s}$ as a function of radius (Figs. 8 and 9).

In the lower mantle, the spectral characteristics of our filtered models are similar to the two S40RTS slices (Figs. 5a and 6a) when $\delta \ln \rho \geq 3.1$. The dominance of power at lower $k$ in such cases is a consequence of the long-wavelength structure of the thermochemical piles. For lower values of $\delta \ln \rho$, power is somewhat randomly spread over wavenumbers $k<20$ beneath the African plate and $k<40$ beneath the Pacific plate, since basaltic piles do not form in as coherent a fashion as at larger density contrasts. Spectral characteristics diverge between the filtered models and S40RTS in the upper mantle, except when $\delta \ln \rho=6.2 \%$, which is the highest value used in 


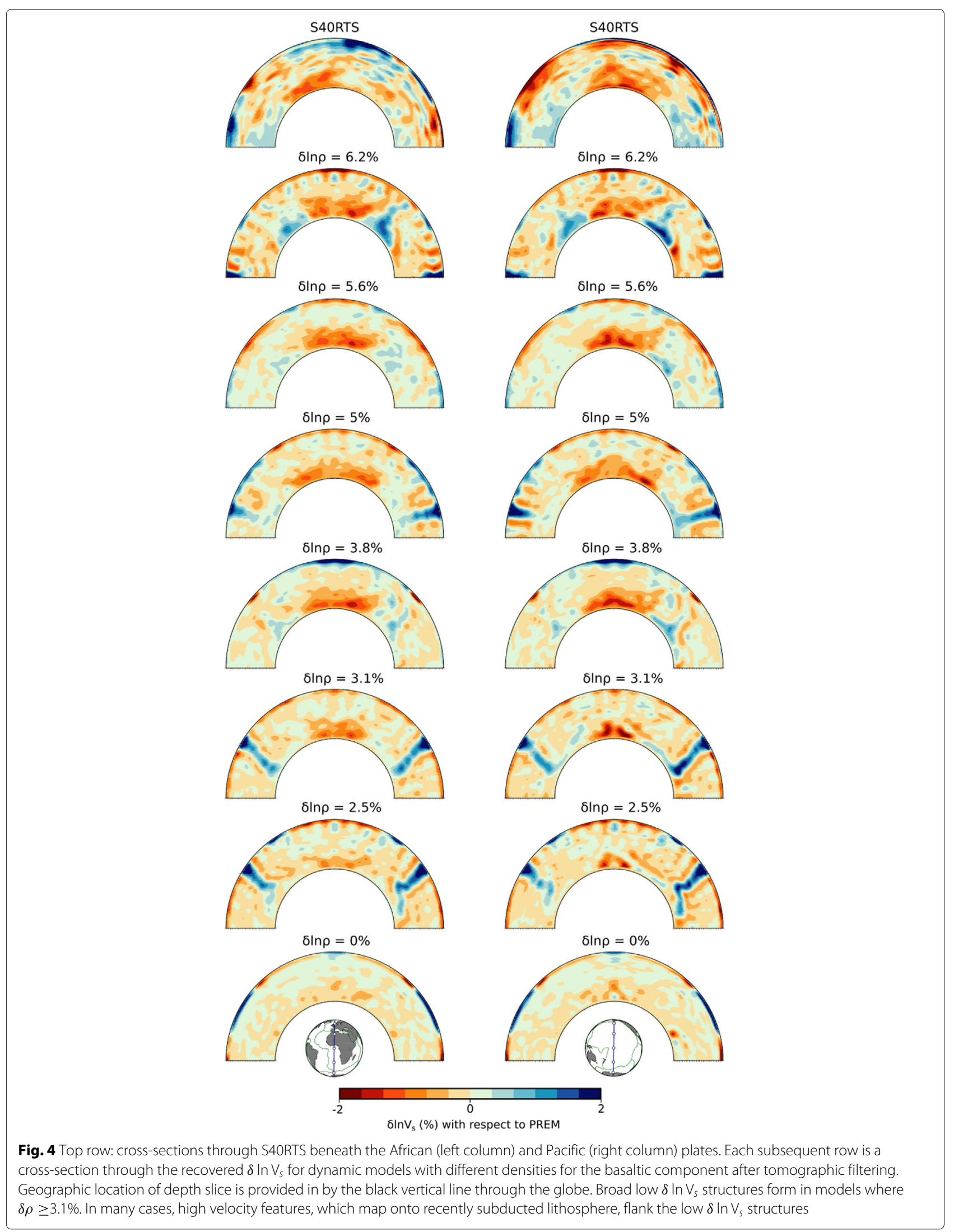




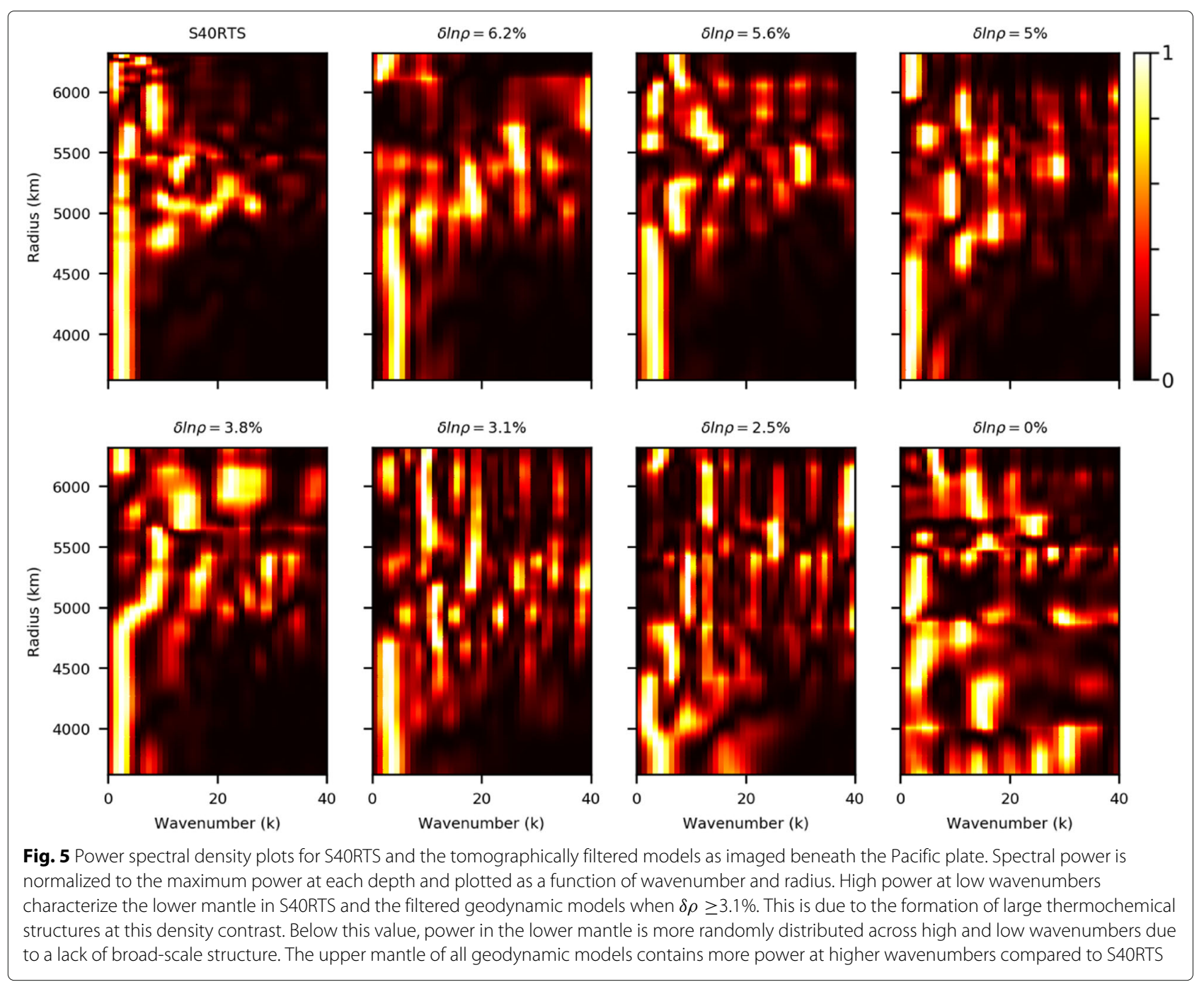

this study. At the scale of our interpretation, the spectral characteristics of LLSVPs in S40RTS do not vary longitudinally. This is illustrated in plots of the spectral content through the Pacific and African LLSVPs spanning $30^{\circ}$ (Fig. 7).

Similar correlations can be observed in the RMS $\delta \ln \mathrm{V}_{s}$ profiles for our filtered models (Figs. 8 and 9). The S40RTS profile is given for comparison. As before, models with $\delta \ln \rho \geq 3.1 \%$ show good correlation to S40RTS in the lower mantle. The larger amplitudes close to the thermal boundary layers and small peaks around the mid-to-upper mantle in S40RTS are poorly matched.

Lastly, we compute the expected $\delta \ln \mathrm{V}_{s} / \delta \ln \mathrm{V}_{p}$ ratio $(\mathrm{S} / \mathrm{P})$ of our models after filtering with the resolution operator of SP12RTS. S/P is calculated by dividing the RMS of $\delta \ln \mathrm{V}_{s}$ by the RMS of $\delta \ln \mathrm{V}_{p}$ at each depth. Figure 10 illustrates $\mathrm{S} / \mathrm{P}$ as a function of radius for the purely thermal case, for the thermochemical cases $\delta \ln \rho=3.1 \%$ and $\delta \ln \rho=6.2 \%$ and for SP12RTS along the same radial segment to which filtering is applied (Fig. 10). Model slices are taken along the same longitude as Pacific mantle sections above but are centered at $15^{\circ}$ latitude where $\mathrm{P}$-wave coverage is higher. In each case, we include the effect of post-perovskite (pPv), whose transition from bridgmanite (brg) increases the amplitude of Vs and thus S/P.

In all filtered models, the increase in $\mathrm{S} / \mathrm{P}$ throughout the lower mantle is comparable to SP12RTS. In the profile shown, the magnitude of S/P of SP12RTS is higher than average due to the presence of the Pacific LLSVP. $S / P$ is weak in the purely thermal case and strengthens in the thermochemical cases as $\delta \ln \rho$ is increased. When $\delta \ln \rho=6.2 \%$, the magnitude of $\mathrm{S} / \mathrm{P}$ far exceeds the maximum values observed in SP12RTS. Peak S/P consistently occurs at $\sim 2500-\mathrm{km}$ depth in our filtered models, which is $\sim 100 \mathrm{~km}$ deeper than in SP12RTS. The same result was 


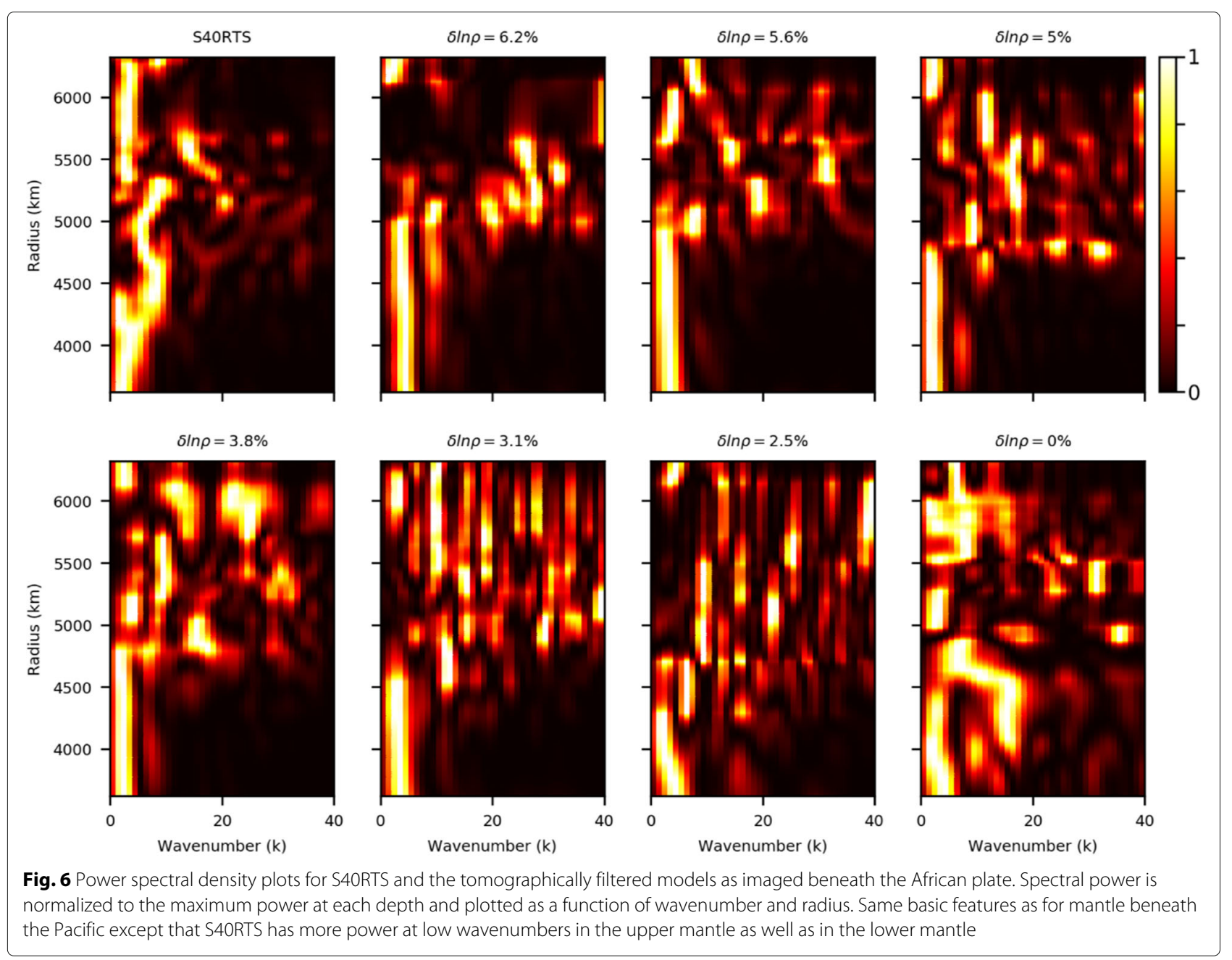

found by Koelemeijer et al. (2018), who proposed two scenarios to resolve the offset: either the Clapeyron slope of the brg-pPv transition shallows at high temperatures or the entire stability field of $\mathrm{pPv}$ occurs at shallower depths.

\section{Discussion}

Our results support the hypothesis that long-term oceanic crust formation and recycling leads naturally to the formation of relatively dense thermochemical piles in the lowermost mantle with characteristics similar to the LLSVPs in S40RTS. We find the best match if the density contrast between basaltic crust and ambient mantle is around $3 \%$ or larger. Note that the precise threshold will depend upon parameters that were not varied in this study but are nonetheless uncertain, such as the temperature dependence of viscosity and the mantle's radial viscosity structure (e.g., Lau et al. 2016).

This interpretation implies a distinct thermal and chemical evolution for the seismic structure of the lower mantle. Piles of basaltic crust have two main attributes that influence $\mathrm{V}_{s}$ : their long residence time at the CMB and their distinct composition. The latter modifies the recovered $\mathrm{V}_{s}$ directly through its effect on the elastic parameters. The former is more important. Initially cold, subducted lithosphere has a high $\mathrm{V}_{s}$. As it warms, basaltic crust segregates from harzburgite and accumulates at the CMB. Stabilized by an excess density, these accumulations become hotter than the ambient mantle and develop a broad thermal halo. The resulting thermochemical structure has seismic characteristics similar to LLSVPs after accounting for tomographic filtering.

Although both former basaltic crust and depleted harzburgite are eventually returned to the upper mantle, the latter has a much shorter residence time in the lower mantle. This has an interesting implication for the evolution of mantle structure. While regions of the lower mantle become increasingly enriched with the accumulation of basalt, the upper mantle becomes increasingly depleted with the addition of harzburgite. Such processes will contribute to the development of the modern depleted upper mantle alongside the extraction of continental crust; a hypothesis also proposed by Campbell (2002). 


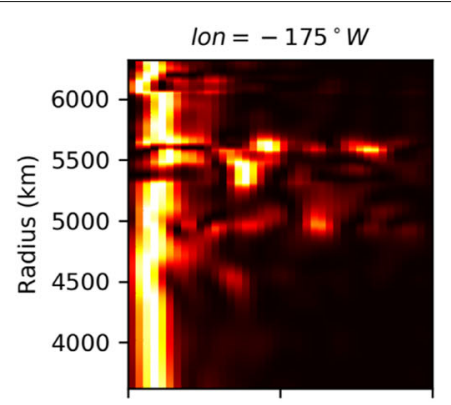

Ion $=-15^{\circ} \mathrm{W}$

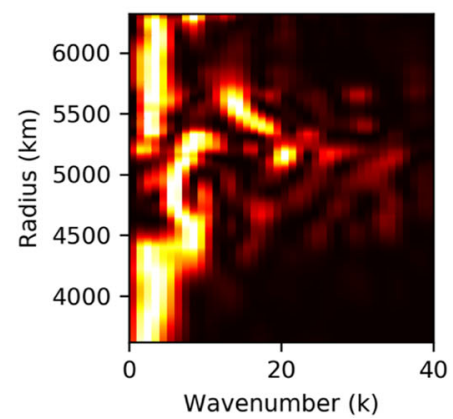

Ion $=-160^{\circ} \mathrm{W}$

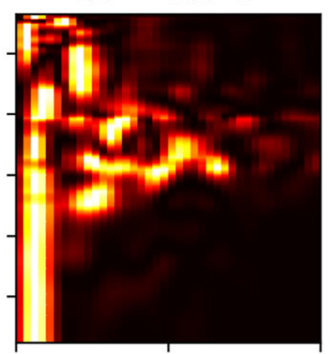

Ion $=0^{\circ}$

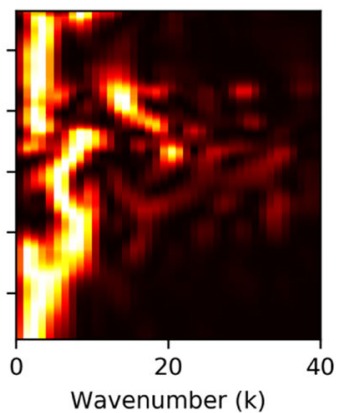

Ion $=-145^{\circ} \mathrm{W}$

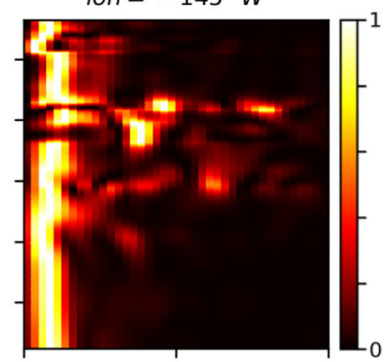

Ion $=15^{\circ} \mathrm{E}$

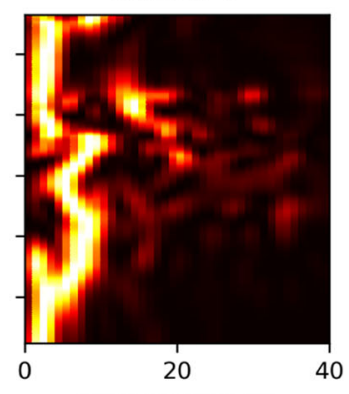

Wavenumber (k)

Fig. 7 Power spectral density plots for S40RTS over $30^{\circ}$ longitude across the Pacific (top row) and African (bottom row) LLSVPs. Spectral power is normalized to the maximum power at each depth and plotted as a function of wavenumber and radius. Over $30^{\circ}$, the broad scale spectral characteristics of both LLSVPs is relatively consistent

Our model predicts that LLSVPs are not fixed features of the mantle in several respects. For one, they are not merely accumulations of basaltic crust but mixtures of basalt, harzburgite, and peridotite, with the concentration of basalt increasing with depth and changing in time. Their shape and size are robust although they become less so with decreasing $\delta \ln \rho$. With lower $\delta \ln \rho$, it becomes easier for subduction to displace the accumulations of oceanic crust. There is no clear indication of the robustness of LLSVPs one way or the other; therefore, a range of dynamic behavior remains plausible.

The influence of long-wavelength thermochemical piles remains pronounced after filtering to the even lower spatial resolution of SP12RTS. However, in the presence of $\mathrm{pPv}$, purely thermal models and thermochemical models produce an increase in lower mantle S/P comparable to SP12RTS. The increase is stronger in thermochemical models and proportional to the density of oceanic crust. For the highest $\delta \ln \rho$ examined here, the amplitude of $\mathrm{S} / \mathrm{P}$ is unrealistically large. Thus $\mathrm{S} / \mathrm{P}$, while not indicative of large scale compositional variation, as demonstrated here and first by Koelemeijer et al. (2018), restricts the maximum density contrast of thermochemical piles. Future work should examine the effect of basaltic crust on S/P in the absence of $\mathrm{pPv}$ and over the full range of experimentally predicted $\delta \ln \rho$.

Oceanic crust recycling also provides an explanation for seismic properties of the lower mantle on a much smaller scale. Haugland et al. (2018) mapped recycled oceanic crust as $\mathrm{P}$ velocity anomalies in the mantle. Their analysis predicts wave-front deflections by fragments of recycled crust. The magnitude of such distortions is sufficient to explain PKIKP precursors between epicentral distances of $130-142^{\circ}$ in both arrival time and magnitude when $\delta \ln \rho \approx 4 \%$ (see Haugland et al. (2018); their Figure 6).

Our study highlights the need for large-scale chemical variation to explain the seismic properties of LLSVPs. This is in disagreement with previous work that has shown thermochemical piles to overpredict the $\delta \ln \mathrm{V}_{s}$ amplitudes of LLSVPs (Bull et al. 2009; Davies et al. 2012, 2015). We suggest that a difference in how thermochemical piles form in each model could explain the discrepancy. In the models of (Bull et al. 2009; Davies et al. 2012, 2015), thermochemical piles form from an initial dense layer above the CMB. The volume of chemically anomalous material is chosen to be $\sim 3 \%$ of the mantle so that it is consistent with volumetric estimates for regions with a pronounced decrease in $V_{s}$ relative to $V_{p}$ (Hernlund and Houser 2008). In our models, thermochemical piles form by the steady accumulation and subsequent warming of dense oceanic crust. After filtering, the resulting $V_{s}$ anomaly is consistent with the size of LLSVPs. However, less than half the size of the anomalous region is chemically distinct from the ambient mantle, and only the bottom $\sim 100 \mathrm{~km}$ approaches pure oceanic crust. Thus, the influence of composition on the seismic properties of thermochemical piles is weakened for two reasons: a smaller portion of their size is chemically distinct and the portion 

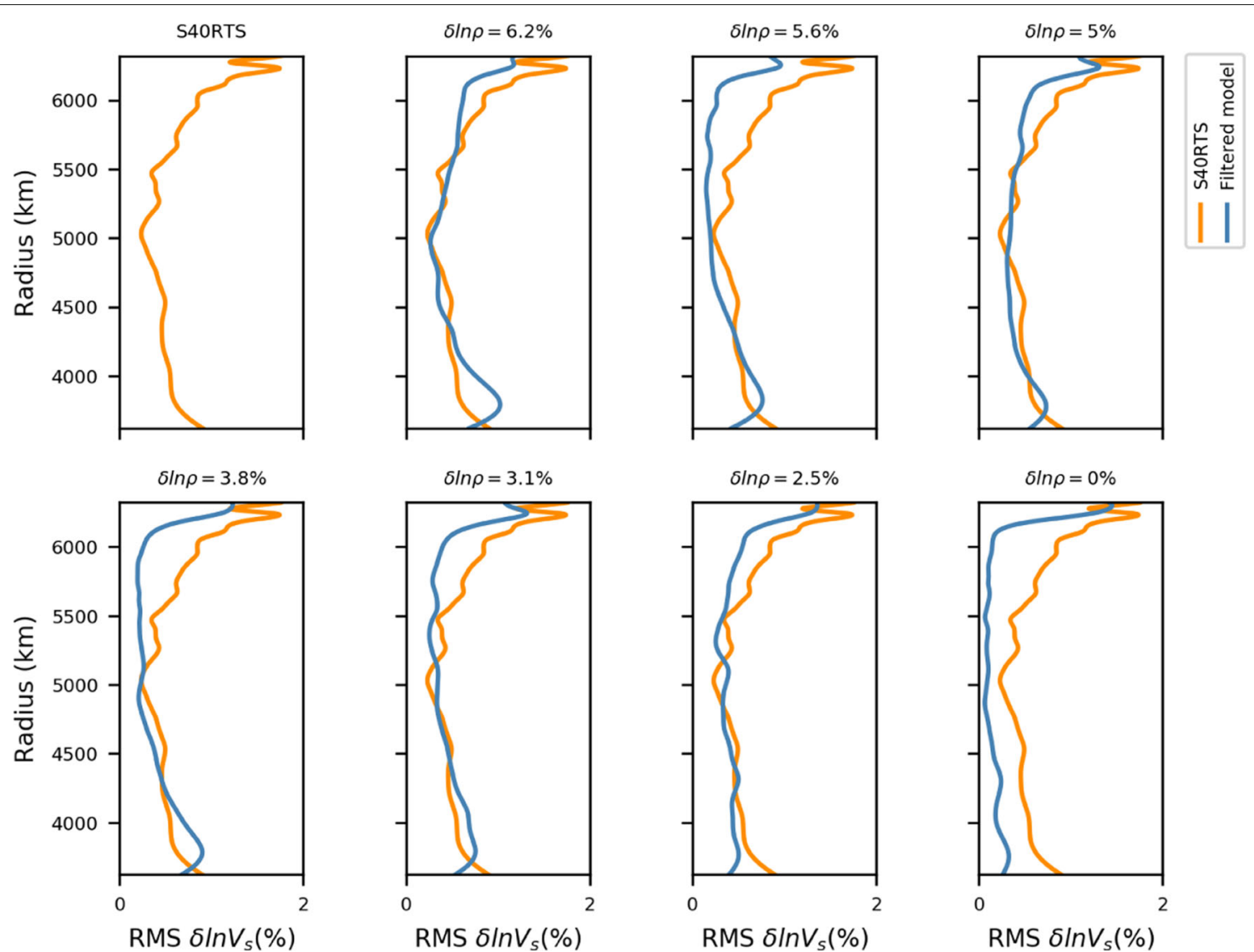

Fig. 8 RMS $\delta \ln V_{s}$ as a function of radius for S40RTS slices (orange) and dynamic models (blue) after tomographic filtering beneath the Pacific plate. RMS $\delta \ln V_{s}$ is poorly matched for all models in the upper mantle. When $\delta \rho \geq 3.1 \%$, the amplitude of RMS $\delta \ln V_{s}$ in the lower mantle can be matched except for the small inflection at the CMB. Overall, RMS $\delta \ln \mathrm{V}_{s}$ is smoother for the filtered models than for S40RTS

that becomes diluted due to mixing with the ambient mantle.

Indeed, without dilution, accumulations of oceanic crust are predicted to yield positive $V_{s}$ anomalies (Deschamps et al. 2012). Deschamps et al. (2012) found that the sensitivity of $\mathrm{V}_{s}$ to oceanic crust in the lowermost mantle is mostly positive and that in order to induce a $\delta \ln \mathrm{V}_{s}$ of $-2.0 \%$, typical of LLSVPs, oceanic crust would have to be $1600 \mathrm{~K}$ above ambient mantle temperature. They concluded that this is unrealistically high and that LLSVPs must therefore not be piles of pure oceanic crust. In contrast, we find that piles consisting of a mixture of oceanic crust, peridotite, and harzburgite require an excess temperature of only $400-700 \mathrm{~K}$ to explain the highest (negative) $\delta \ln \mathrm{V}_{s}$ amplitudes of LLSVPs.

Although we find that thermal heterogeneity plays a dominant role in LLSVP formation, our study is also in contrast with previous work suggesting that the LLSVPs could be purely thermal (Schubert et al. 2004; Schuberth et al. 2009; Bull et al. 2009; Davies et al. 2012, 2015; Koelemeijer et al. 2018) as we find that some dense compositional component is required. This discrepancy may be explained by the organizing effect of plate-motion history. In previous studies where past plate motions are imposed at the model surface, the formation of longwavelength and strong amplitude velocity structures is attributed to the organizing force of Earth's particular tectonic history and form whether compositional variations are present or not. The influence of past plate motions cannot be explored in our 2D geometry.

We cannot exclude the importance of primordial heterogeneity that may still be sequestered near the base of the mantle (e.g., Tackley 1998; and Labrosse et al. 2007). In fact, geochemical arguments based on mantle noble gas chemistry (e.g., Allègre et al. 1996; and Albarède 1998) and studies of short-lived isotope systems (e.g., Boyet and Carlson 2005; and Rizo et al. 2016) strongly suggest that primordial heterogeneity has been preserved in the Earth's mantle. From these studies, it is not clear however what the required volume for preservation is. We share the view, suggested in previous studies (e.g., Tackley 2012; Li et al. 2014; and Ballmer et al. 2016), that there likely is a combination of both primordial chemical heterogeneity and recycled oceanic crust that contributes 

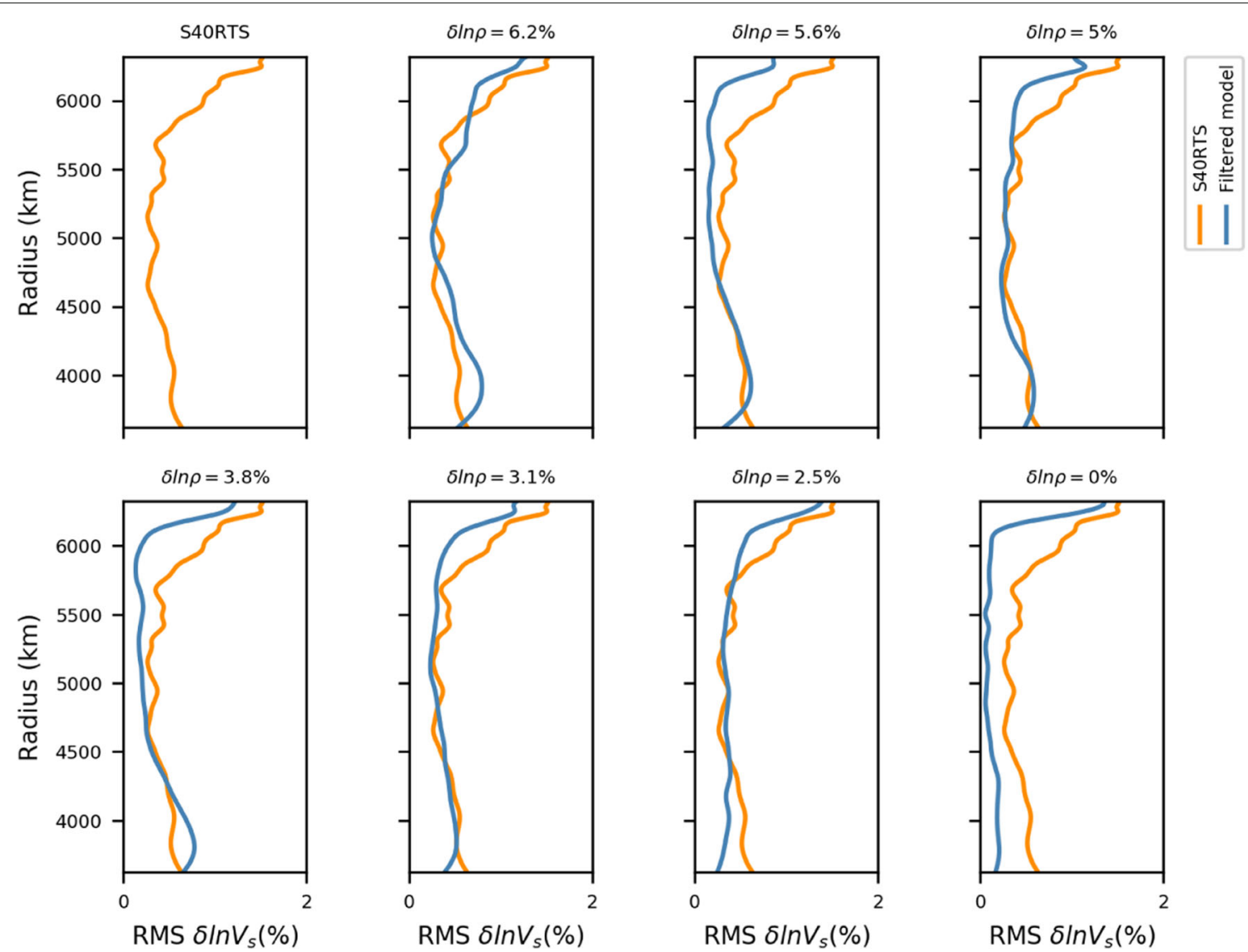

Fig. 9 RMS $\delta \ln V_{s}$ as a function of radius for S40RTS slices (orange) and dynamic models (blue) after tomographic filtering beneath the African plate

to the observed structure of the LLSVPs. Teasing out their relative contributions will require further interdisciplinary work combining geodynamics and geochemistry (as in CH94; van Keken and Ballentine 1998, 1999); Xie and Tackley 2004; Jackson et al. 2018) with further seismological analyses as, for example, in this paper or Haugland et al. (2018) .

Clear improvements to the models that can be made include (i) compressible convection, (ii) better representation of the spherical geometry, and (iii) more flexible implementation of plate tectonics. As for (i), the use of full compressible mantle convection (e.g., Nakagawa et al. 2010; and Bossmann and van Keken 2013) will allow for the self-consistent implementation of phase changes and realistic equation of state. This will allow for an improved and more consistent comparison with the seismological observations and models. As for (ii), while we expect eventually to be able to perform full 3D simulations such as in Nakagawa et al. (2010) and Barry et al. (2017), the required high resolution and time evolution over the age of the Earth makes the use of 2D geometries still highly attractive. In BB08, a cylindrical "shrunken core" approach was used to better represent the heat loss properties of the Earth. The "spherical annulus" geometry of Hernlund and Tackley (2008) provides a more natural approach that, while $2 \mathrm{D}$, represents the additional curvature by mapping of the equations onto a spherical cross section that retains the appropriate scaling between CMB radius and Earth's radius. As for (iii), we use a formulation for introducing tectonic plate into the models that is based on defining the plate geometry and computing the velocity of each plates by integrating the stress that the underlying convection exerts on them. This approach, first introduced by Gable et al. (1991), has the advantage over kinematically prescribing plates (e.g., Christensen and Hofmann 1994; and Davies et al. 2012) that the formulation is energy conservative and that one can reach Earth-like convective vigor without significant computational issues. An interesting alternative is the use of the "yield-stress" rheology (e.g., Tackley 2000) which has been demonstrated to lead to plate-like behavior without the requirement of prescribing the geometry of the plates. While it is still a question whether plate-like velocities can be modeled with this approach, recent advances using continental rafts suggest 


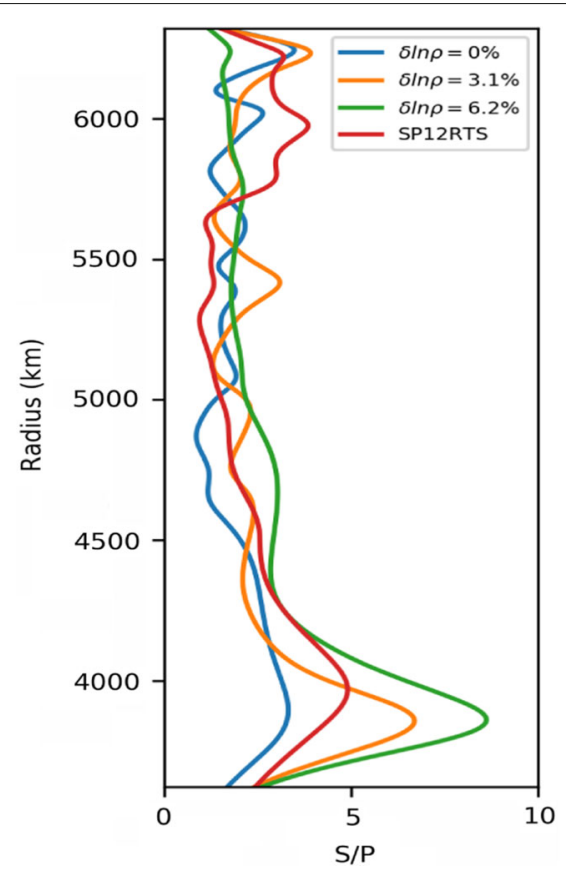

Fig. $10 \mathrm{~S} / \mathrm{P}$ plotted against radius, where $S / P$ is the ratio RMS $\delta \ln V_{s} / \mathrm{RMS} \delta \ln \mathrm{V}_{p}$. Model slices are taken along the same longitude as Pacific mantle segments in previous plots except they are centered at $15^{\circ}$ latitude where $\mathrm{P}$-wave coverage is higher

Earth-like convective vigor may be in reach (e.g., Arnould et al. 2018; Coltice et al. 2013; and Rolf et al. 2018).

\section{Conclusions}

In summary, we have shown that oceanic crust formation and recycling as modeled by BB08 can satisfactorily explain the LLSVPs in both the size and amplitude of the shear-wave anomalies as long as oceanic crust is denser than ambient mantle by $3 \%$ or more. The LLSVPs formed in our models are not composed solely of oceanic crust. Rather, they are basalt rich at their base (bottom $100-200 \mathrm{~km}$ ) and grade into peridotite toward their sides and top. The strength of their seismic signature arises from warming over billions of years. These models appear to be well suited as base models for further exploration of the interplay between geodynamical and geochemical processes that lead to the long-term chemical and thermal evolution of the Earth. These models have been shown to match the present-day surface velocities and heat flow characteristics of the Earth, match the required outgassing efficiency of the crust and manthe as evidenced from ${ }^{40} \mathrm{Ar}$, and match to a reasonable extent the HIMU-DMM-EM1 characteristics observed in OIBs and MORBs (BB08). This latter point has been further demonstrated by including the Lu-Hf isotope system (Jones et al. 2019).

\section{Abbreviations}

CMB: Core-mantle boundary; DMM: Depleted MORB mantle; EED: Eclogite excess density as defined by $R c / R a$ (as in Brandenburg et al. 2008); EMI: Enriched mantle type 1; HIMU: High original $\mu$ where $\mu=\mathrm{U} / \mathrm{Pb}$; MORB: Mid-oceanic ridge basalt; OIB: Oceanic island basalt

\section{Acknowledgements}

We thank two anonymous reviewers for their constructive comments and questions, which led to better versions of the ideas presented in this paper. PVK and JR gratefully acknowledge partial travel support from the Japanese Geosciences Union to the 2014 SEDI meeting in Kanagawa, Japan.

\section{Authors' contributions}

TJ and RM performed the modeling, analysis, and interpretation of the results. PvK and JR designed the study and contributed to the dynamical models. JR and PK provided the seismic filtering software. The authors read and approved the final manuscript.

\section{Funding}

This work was partly funded through the National Science Foundation grants EAR CSEDI 1664642 and EAR CSEDI 0855487.

\section{Availability of data and materials}

The manuscript does not contain original data. The models are available from the authors upon request.

\section{Competing interests}

The authors declare that they have no competing interests.

\section{Author details}

${ }^{1}$ Department of Terrestrial Magnetism, Carnegie Institution for Science, 5241 Broad Branch Road NW, Washington, DC, 20015 USA. ${ }^{2}$ Department of Geology, University of Maryland, 8000 Regents Drive, College Park, MD, 20742, USA. ${ }^{3}$ Department of Earth and Planetary Sciences, University of New Mexico, 221 Yale Blvd NE, Albuquerque, NM, 87131, USA. ${ }^{4}$ Department of Earth and Environmental Sciences, University of Michigan, 1100 North University Avenue, Ann Arbor, MI, 40819, USA. ${ }^{5}$ Department of Earth and Sciences, Royal Holloway University of London, Egham Hill, Egham, Surrey, TW20 OEX, UK.

Received: 9 October 2019 Accepted: 26 March 2020

Published online: 21 May 2020

\section{References}

Akbarashrafi F, Al-Attar D, Deuss A, Trampert J, Valentine A (2018) Exact free oscillation spectra, splitting functions and the resolvability of Earth's density structure. Geophys J Int 213(1):58-76

Albarède F (1998) Time-dependent models of U-Th-He and K-Ar evolution and the layering of mantle convection. Chem Geol 145:413-429

Allègre C. J, Hofmann A, O'Nions K (1996) The argon constraints on mantle structure. Geoph Res Lett 23:3555-3557

Aoki I, Takahashi E (2004) Density of MORB eclogite in the upper mantle. Phys Earth Planet Inter 143:129-143

Arnould M, Coltice N, Flament N, Seigneur V, Müller RD (2018) On the scales of dynamic topography in whole-mantle convection models. Geochem Geophys Geosyst 19:3140-3163

Baker MB, Beckett JR (1999) The origin of abyssal peridotites: a reinterpretation of constraints based on primary bulk compositions. Earth Planet Sci Lett 171(1):49-61

Ballmer M. D, Schumacher L, Lekic V, Thomas C, Ito G (2016) Compositional layering within the large low shear-wave velocity provinces in the lower mantle. Geochem Geophys Geosyst 17(12):5056-5077

Barry TL, Davies JH, Wolstencroft M, Millar IL, Zhao Z, Jian P, Safonova I, Price M (2017) Whole-mantle convection with tectonic plates preserves long-term global patterns of upper mantle geochemistry. Sci Rep 7:1870

Bossmann AB, van Keken PE (2013) Dynamics of plumes in a compressible mantle with phase changes: implications for phase boundary topography. Phys Earth Planet Inter 224:21-31

Boyet M, Carlson RW (2005) ${ }^{142} \mathrm{Nd}$ evidence for early (>4.53 Ga) global differentiation of the silicate Earth. Science 309:576-581 
Brandenburg JP, van Keken PE (2007) Deep storage of oceanic crust in a vigorously convecting mantle. J Geophys Res. 112: B06403. https://doi.org/ 10.1029/2006jb004813

Brandenburg JP, Hauri EH, van Keken PE, Ballentine CJ (2008) A multiple-system study of the geochemical evolution of the mantle with force-balanced plates and thermochemical effects. Earth Planet Sci Lett 276:1-13

Bull AL, McNamara AK, Ritsema J (2009) Synthetic tomography of plume clusters and thermochemical piles. Earth Planet Sci Lett 278(3-4):152-162

Burke K, Steinberger B, Torsvik TH, Smethurst MA (2008) Plume generation zones at the margins of large low shear velocity provinces on the core-mantle boundary. Earth Planet Sci Lett 265:49-60

Campbell IH (2002) Implications of Nb/U, Th/U and Sm/Nd in plume magmas for the relationship between continental and oceanic crust formation and the development of the depleted mantle. Geochim Cosmochim Acta 66(9):1651-1661

Christensen UR, Hofmann AW (1994) Segregation of subducted oceanic crust in the mantle. J Geophys Res 99:19867-19884

Coltice N, Seton M, Rolf T, Müller RD, Tackley PJ (2013) Convergence of tectonic reconstructions and mantle convection models for significant fluctuations in seafloor spreading. Earth Planet Sci Lett 383:92-100

Connolly JAD (2005) Computation of phase equilibria by linear programming: a tool for geodynamic modeling and its application to subduction zone decarbonation. Geophys J Int 236:524-541

Cottaar S, Lekic V (2016) Morphology of seismically slow lower-mantle structures. Geophys J Int 207:1122-1136

Davies GF (2002) Stirring geochemistry in mantle convection models with stiff plates and slabs. Geochim Cosmochim Acta 66:3125-3142

Davies DR, Goes S, Davies JH, Schuberth BA, Bunge H, Ritsema J (2012) Reconciling dynamic and seismic models of Earth's lower mantle: the dominant role of thermal heterogeneity. Earth Planet Sci Lett 353:253-269

Davies DR, Goes S, Lau HCP (2015) Thermally dominated deep mantle LLSVPs: a review. In: Khan A, Deschamps F (eds). The Earth's Heterogeneous Mantle. Springer, Switzerland. pp 441-477

Deschamps F, Cobden L, Tackley PJ (2012) The primitive nature of large low shear-wave velocity provinces. Earth Planet Sci Lett 349:198-208

Dziewonski AM, Hager BH, O'Connell RJ (1977) Large-scale heterogeneities in the lower mantle. J Geophys Res 82:239-255

Gable CW, O'Connell RJ, Travis BJ (1991) Convection in three dimensions with surface plates: generation of toroidal flow. J Geophys Res 96:8391-8405

Garnero E, McNamara AK (2008) Structure and dynamics of Earth's lower mantle. Science 320:626-628

Grand S, van der Hilst RD, Widiyantoro S (1997) Global seismic tomography: a snapshot of mantle convection in the Earth. GSA Today 7:1-7

Haugland SM, Ritsema J, van Keken PE, Nissen-Meyer T (2018) Analysis of PKP scattering using mantle mixing simulations and axisymmetric 3D waveforms. Phys Earth Planet Inter 276:226-233

Hernlund JW, Houser C (2008) On the statistical distribution of seismic velocities in Earth's deep mantle. Earth and Planet Sci Let 265(3-4):423-437

Hernlund JW, Tackley PJ (2008) Modeling mantle convection in the spherical annulus. Phys Earth Planet Inter 171:48-54

Hirose K, Fei Y, Ma Y, Mao H-K (1999) The fate of subducted basaltic crust in the Earth's lower mantle. Nature 397:53-56

Hirose K, Takafuji N, Sata N, Ohishi Y (2005) Phase transition and density of subducted MORB crust in the lower mantle. Earth Planet Sci Lett 237:239-251

Hofmann AW, White WM (1982) Mantle plumes from ancient oceanic crust. Earth Planet Sci Lett 57:421-436

Ishii M, Tromp J (1999) Normal-mode and free-air gravity constraints on lateral variations in velocity and density of Earth's mantle. Science 285(5431):1231-1236

Jackson MG, Becker TW, Konter JG (2018) Geochemistry and distribution of recycled domains in the mantle inferred from $\mathrm{Nd}$ and $\mathrm{Pb}$ isotopes in oceanic hot spots: implications for storage in the large low shear wave velocity provinces. Geochem Geophys Geosyst 19:3496-3519

Jones RE, van Keken PE, Hauri EH, Vervoort J, Ballentine CJ (2019) Origins of the terrestrial $\mathrm{Hf}-\mathrm{Nd}$ mantle array: evidence from a combined geodynamical-geochemical approach. Earth Planet Sci Lett 518:26-39

Kennett BLN, Widiyantoro S, van der Hilst RD (1998) Joint seismic tomography for bulk sound and shear wave speed in the Earth's mantle. J Geophys Res 103:12469-12493
Koelemeijer P, Ritsema J, Deuss A, Van Heijst H-J (2016) SP12RTS: a degree-12 model of shear-and compressional-wave velocity for Earth's mantle. Geophys J Int 204(2):1024-1039

Koelemeijer P, Deuss A, Ritsema J (2017) Density structure of Earth's lowermos mantle from Stoneley mode splitting observations. Nature Commun. 8: 15241. https://doi.org/10.1038/ncomms15241

Koelemeijer P, Schuberth BS, Davies DR, Deuss A, Ritsema J (2018) Constraints on the presence of post-perovskite in Earth's lowermost mantle from tomographic-geodynamic model comparisons. Earth Planet Sci Lett 494:226-238

Labrosse S, Hernlund JW, Coltice N (2007) A crystallizing dense magma ocean at the base of the Earth's mantle. Nature 450:866-869

Lau HC, Mitrovica JX, Austermann J, Crawford O, Al-Attar D, Latychev K (2016) Inferences of mantle viscosity based on ice age data sets: radial structure. J Geophys 121(10):6991-7012

Lau HCP, Mitrovica JX, Davis JL, Tromp J, Yang H-Y, Al-Attar D (2017) Tidal tomography constrains Earth's deep-mantle buoyancy. Nature 551:321-326

Lee C-TA, Luffi P, Höink T, Li J, Dasgupta R, Hernlund J (2010) Upside-down differentiation and generation of a 'primordial' lower mantle. Nature 463:930-933

Li M, McNamara AK (2013) The difficulty for subducted oceanic crust to accumulate at the Earth's core-mantle boundary. J Geophys 118:1807-1816

Li M, McNamara AK, Garnero EJ (2014) Chemical complexity of hotspots caused by cycling oceanic crust through mantle reservoirs. Nat Geosci 7(5):366

Maguire R, Ritsema J, van Keken PE, Fichtner A, Goes S (2016) P- and S-wave delays caused by thermal plumes. Geophys J Intern 206:1169-1178

Masters G, Laske G, Bolton H, Dziewonski A (2000) The relative behavior of shear velocity, bulk sound speed, and compressional velocity in the mantle: implications for chemical and thermal structure. In: Karato S-I, Forte A, Liebermann R, Masters G, Stixrude L (eds). Earth's Deep Interior: Mineral Physics and Tomography from the Atomic to the Global Scale, Geophysical Monograph Series, vol 117. American Geophysical Union, Washington DC. pp 63-87

McNamara AK, Zhong S (2005) Thermo-chemical structures beneath Africa and the Pacific Ocean. Nature 437:1136-1139

McNamara AK (2019) A review of large low shear velocity provinces and ultra low velocity zones. Tectonophysics 760:199-220

Moulik P, Ekström G (2016) The relationships between large-scale variations in shear velocity, density, and compressional velocity in the Earth's mantle. J Geophys Res 121(4):2737-2771

Nakagawa T, Tackley PJ (2008) Lateral variations in CMB heat flux and deep mantle seismic velocity caused by a thermal-chemical-phase boundary layer in 3D spherical convection. Earth Planet Sci Lett 271:348-358

Nakagawa T, Tackley PJ, Deschamps F, Connolly JA (2009) Incorporating self-consistently calculated mineral physics into thermochemical mantle convection simulations in a 3-D spherical shell and its influence on seismic anomalies in Earth's mantle. Geochem Geophys Geosys. 10: Q03004. https://doi.org/10.1029/2008gc002280

Nakagawa T, Tackley PJ, Deschamps F, Connolly JAD (2010) The influence of MORB and harzburgite composition on thermo-chemical mantle convection in a 3-D spherical shell with self-consistently calculated mineral physics. Earth Planet Sci Lett 296:403-412

Ni S, Tan E, Gurnis M, Helmberger D (2002) Sharp sides to the African superplume. Science 296:1850-1852

Ricolleau A, Perrillat J-P, Fiquet G, Daniel I, Matas J, Addadd A, Menguy N, Cardon H, Mezouar M, Guignot N (2010) Phase relations and equation of state of a natural MORB: implications for the density profile of subduction oceanic crust in the Earth's lower mantle. 115: B08202. https://doi.org/10. 1029/2009jb006709

Ringwood A. E, Irifune T (1988) Nature of the 650-km seismic discontinuity: implications for mantle dynamics and differentiation. Nature 331:131-136

Ringwood A. E (1990) Phase transformations and differentiation in subducted lithosphere: implications for mantle dynamics, basalt petrogenesis, and crustal evolution. J Geol 90:611-643

Ritsema J, Lay T, Garnero EJ, Benz H (1998) Seismic anisotropy in the lowermost mantle beneath the Pacific. Geophys Res Lett 25(8):1229-1232

Ritsema J, McNamara AK, Bull A (2007) Tomographic filtering of geodynamic models: implications for model interpretation and large-scale mantle structure. J Geophys Res. 112: B01303. 
Ritsema J, Deuss A, van Heijst HJ, Woodhouse JH (2011) S40RTS: a degree-40 shear-velocity model for the mantle from new Rayleigh wave dispersion, teleseismic traveltime and normal-mode splitting function measurements. Geophys J Int 184:1223-1236

Rizo H, Walker RJ, Carlson RW, Horan MF, Mukhopadhyay S, Manthos V, Francis D, Jackson MG (2016) Preservation of earth-forming events in the tungsten isotopic composition of modern flood basalts. Science 352:809-812

Robertson GS, Woodhouse JH (1995) Evidence for proportionality of P and S heterogeneity in the lower mantle. Geophys J Int 123:85-116

Rolf T, Capitanio FA, Tackley PJ (2018) Constraints on mantle viscosity structure from continental drift histories in spherical mantle convection models. Tectonophysics 746:339-351

Romanowicz B (2001) Can we resolve 3-D density heterogeneity in the lower mantle? Geophys Res Lett 28:1107-1110

Schubert G, Masters G, Olson P, Tackley P (2004) Superplumes or plume clusters? Phys Earth Planet Inter 146:147-162

Schuberth BSA, Bunge H, Steinle-Neumann G, Moder C, Oeser J (2009) Thermal versus elastic heterogeneity in high-resolution mantle circulation models with pyrolite composition: high plume excess temperatures in the lowermost mantle. Geochem Geophys Geosys. 10: Q01W01. https://doi. org/10.1029/2008gc002235

Stixrude L, Lithgow-Bertelloni C (2011) Thermodynamics of mantle minerals II, phase equilibria. Geophys J Int 184:1180-1213

Tackley PJ (1998) Three-dimensional simulations of mantle convection with a thermo-chemical basal boundary layer: D. Core-Mantle Bound Reg Geodyn Ser 28:231-253

Tackley PJ (2000) Mantle convection and plate tectonics: toward an integrated physical and chemical theory. Science 288:2002-2007

Tackley PJ (2012) Three-dimensional simulations of mantle convection with a thermo-chemical basal layer: D"?. In: Gurnis M, Wysession ME, Knittle E, Buffett BA (eds). The Core-Mantle Boundary. AGU, Washington. pp 231-53

Tanaka S, Suetsugu D, Shiobara H, Sugioka H, Kanazawa T, Fukao Y, Barruol G, Reymond D (2009) On the vertical extent of the large low shear velocity province beneath the South Pacific Superswell. Geophys Res Lett. 36: L07305. https://doi.org/10.1029/2009gl037568

Trampert J, Deschamps F, Resovsky J, Yuen D (2004) Probabilistic tomography maps chemical heterogeneities throughout the lower mantle. Science 124(5697):942-926 942-926

Tsuchiya T (2011) Elasticity of subducted basaltic crust at the lower mantle pressures: insights on the nature of deep mantle heterogeneity. Phys Earth Planet Inter 188:142-149

van Keken PE (2001) Cylindrical scaling for dynamical cooling models of the Earth. Phys Earth Planet Inter. https://doi.org/10.1016/s00319201(01)00195-9

van Keken PE, Ballentine CJ (1998) Whole-mantle versus layered mantle convection and the role of a high-viscosity lower mantle in terrestrial volatile evolution. Earth Planet Sci Lett 156:19-32

van Keken PE, Ballentine CJ (1999) Dynamical models of mantle volatile evolution and the role of phase transitions and temperature-dependent rheology. J Geophys Res 104:7137-7151

Workman RK, Hart SR (2005) Major and trace element composition of the depleted MORB mantle (DMM). Earth Planet Sci Lett 231:53-72

Xie S, Tackley PJ (2004) Evolution of U-Pb and Sm-Nd systems in numerical models of mantle convection. J Geophys Res. 109: B11204.

Xu W, Lithgow-Bertelloni C, Stixrude L, Ritsema J (2008) The effect of bulk composition and temperature on mantle seismic structure. Earth Planet Sci Lett 275:70-79

\section{Publisher's Note}

Springer Nature remains neutral with regard to jurisdictional claims in published maps and institutional affiliations.

\section{Submit your manuscript to a SpringerOpen ${ }^{\circ}$ journal and benefit from:}

\section{- Convenient online submission}

- Rigorous peer review

- Open access: articles freely available online

- High visibility within the field

- Retaining the copyright to your article

Submit your next manuscript at $\gg$ springeropen.com 